\title{
Profile of Liver Fine Needle Aspiration in Tertiary Care Hospital
}

Sunita Singh, Rajeev Sen, Sanjay Kumar, Sumiti Gupta, Sonia Chhabbra, Monika Sangwan, Sunil Lamba

\begin{abstract}
Objective: This retrospective study was planned to evaluate role of fine needle aspiration cytology (FNAC) in space occupying lesions of liver as first line investigation to differentiate benign from malignant pathologies, primary vs secondary malignancies and establishing exact diagnosis.
\end{abstract}

Materials and methods: A total number of 81 ultrasonography (USG)-guided FNA liver were performed in Postgraduate Institute of Medical Sciences (P GIMS), R ohtak from J une 2010 to May 2011. Wet fixed and air dried smears were stained with Papanicolaou and May-Grunwald-Giemsa respectively.

Results: Age ranged from 19 to 86 years. Sixty-seven out of 81 cases were conclusive. Four out of 67 were benign. 0 ut of remaining 63 malignant, six were primary lesions including four cases of hepatocellular carcinoma, one of Burkitt's lymphoma and one of cholangiocarcinoma. Secondary metastatic lesions were 44 including metastasis from malignant melanoma, squamous cell carcinoma and leiomyosarcoma.

Conclusion: USG-guided FNAC is very useful tool in establishing diagnosis of hepatic lesions as the procedure is simple, safe and minimally invasive.

Keywords: Ultrasonography-guided FNAC, First line of investigation, Simple, Safe, Minimally invasive.

How to cite this article: Singh S, Sen R, Kumar S, Gupta S, Chhabbra S, Sangwan M, Lamba S. P rofile of Liver Fine Needle Aspiration in Tertiary Care Hospital. Euroasian J HepatoGastroenterol 2013;3(1):31-35.

\section{Source of support: $\mathrm{Nil}$}

Conflict of interest: None

\section{INTRODUCTION}

Ultrasonography-guided fine needle aspiration cytology (FNAC) has now been emerged as a very simple, safe, inexpensive, minimally invasive and rapid method for cytopathological evaluation of liver lesions. It has replaced conventional large needle core biopsies in diagnosis of focal liver lesions. The main advantage of it is the possibility of multiple passes, which increases the chances of obtaining adequate viable cells, especially in necrotic tumors. ${ }^{1}$ USG guided FNA C is primarily employed to differentiate benign from malignant pathologies, primary vs secondary malignancies and establishing the exact diagnosis and their correlation with clinical presentation and radiological imaging investigations wherever possible. The main indication of FNAC of liver are single or multiple nodular lesions, demonstrated clinically by palpation or radiologically on computer tomography (CT) or USG. There are only few contraindications to this procedure which are hemorrhagic diathesis and various vascular lesions. ${ }^{2-4}$ The aim of our study is to evaluate the role of USG -guided FNAC as a first line of investigation to establish the exact and early diagnosis of space occupying lesions of liver and also to study the cytomorphological features of various lesions with histopathology whenever possible.

\section{MATERIALS AND METHODS}

A total number of all 81 USG-guided FNAC were performed on liver lesions diagnosed clinically or radiologically, with normal range of prothrombin time index at PGIM S, Rohtak over a period of 1 year from June 2010 to M ay 2011. Aspirates were obtained with a 21 or 22 gauge needle attached to a $20 \mathrm{ml}$ syringe and smears were made as quickly as possible. Some smears were air dried for $M$ ay-GrunwaldGiemsa. One smear was wet fixed in $95 \%$ alcohol for Papanicolaou or hematoxylin and eosin (H\&E). The blood clots fixed in $10 \%$ neutral buffered formalin were al so used for histopathology. These were processed in automatic tissue processor and $H \& E$ staining was done. Cytological diagnosis were made and confirmed on histopathology and with immunohistochemical (IHC) staining wherever possible.

\section{RESULTS}

A total of 81 cases were aspirated during this duration of 1 year and studied. A ge group ranged from 19 to 86 years with maximum cases lying in between 41 and 75 years. $M$ ale to female ratio was nearly normal. The patient's main complaints were pain in right upper quadrant of abdomen, anorexia, weight loss, abdominal mass and hepatosplenomegaly. Some also presented with ascites, abdominal distension, pruritus, jaundice and fever. Time period of complaints varied from 7 days to 7 months. A fter screening smears, results were categorized as benign aspirates, malignant aspirates, suspicious of malignancy and nonrepresentative (Table 1). Thus finally, 67 cases were conclusive giving a diagnostic yield of $82.7 \%$. O ut of these 67 cases, four (6\%) patients were having benign lesions with three (4.5\%) of them have abscess (Fig. 1) and one (1.5\%) was diagnosed for liver cell dysplasia (Fig. 2). Six $(9 \%)$ cases were primary malignant lesions which constitutes hepatocellular carcinoma (HCC; 6\%) (Fig. 3), Burkitt's 
lymphoma (1.5\%) (Figs 4 and 5) and cholangiocarcinoma (1.5\%). Secondary metastatic lesions compose $65.7 \%$ of cases and adenocarcinoma (32.8\%) was the commonest type. A total of $28.4 \%$ were categorized as poorly differentiated carcinoma. M etastasis from malignant melanoma (1.5\%) (Fig. 6), squamous cell carcinoma (1.5\%), and leiomyosarcoma (1.5\%), were also diagnosed and confirmed on IHC (Table 2). Patients were followed for clinical history and radiological details to know primary site of secondaries in liver. Primary was known in $35(61.4 \%)$ cases and unknown in remaining 22 (38.6\%) cases. M aximum metastasis was from gut and gall bladder

\section{Table 1: Cytological categorization of liver aspirates}

\begin{tabular}{clcc} 
SI. no. & Liver aspirates & No. of cases & Percentage \\
\hline 1. & Benign aspirates & 04 & 04.9 \\
2. & Malignant aspirates & 51 & 61.7 \\
3. & Suspicious of malignancy & 13 & 16 \\
4. & Nonrepresentative & 4 & 17.2 \\
\hline & Total & 81 & 100 \\
\hline
\end{tabular}

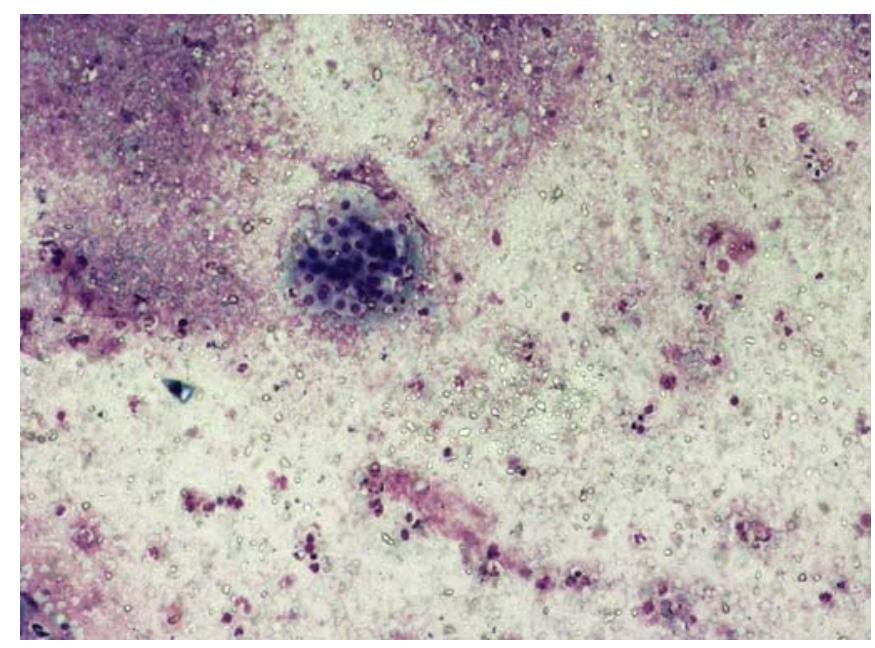

Fig. 1: A case of abscess hepatocytes and inflammatory cells at $200 x$

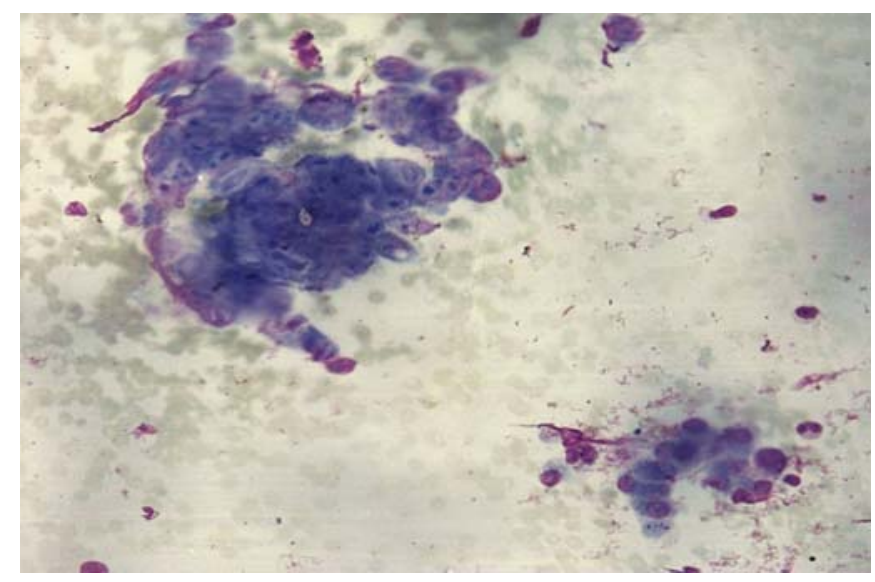

Fig. 2: A case of liver cell dysplasia showing high N/C ratio of hepatocytes at $400 x$ carcinoma. Primary was also located in pancreas, breast, lung, penile, endometrium, adrenal mass and melanoma (Fig. 7).

\section{DISCUSSION}

FNAC is very useful procedure for the diagnosis of various hepatic lesions. It offers accuracy without major complications and minimal intervention at low cost. ${ }^{5}$ The patients main complaints were, pain abdomen right upper quadrant, anorexia, weight loss, abdominal mass and hepatosplenomegaly. Some also presented with ascites, abdominal distension, pruritus, jaundice and fever. Exact management of hepatic lesions is a common clinical problem and their appropriate management depends on accurate diagnosis. ${ }^{6}$ The differential diagnosis of hepatic mass lesions includes primary liver tumors, metastatic deposits, congenital and acquired cysts, abscesses and granulomas. On imaging techniques the appearances are often nonspecific. There is some overlap between radiological

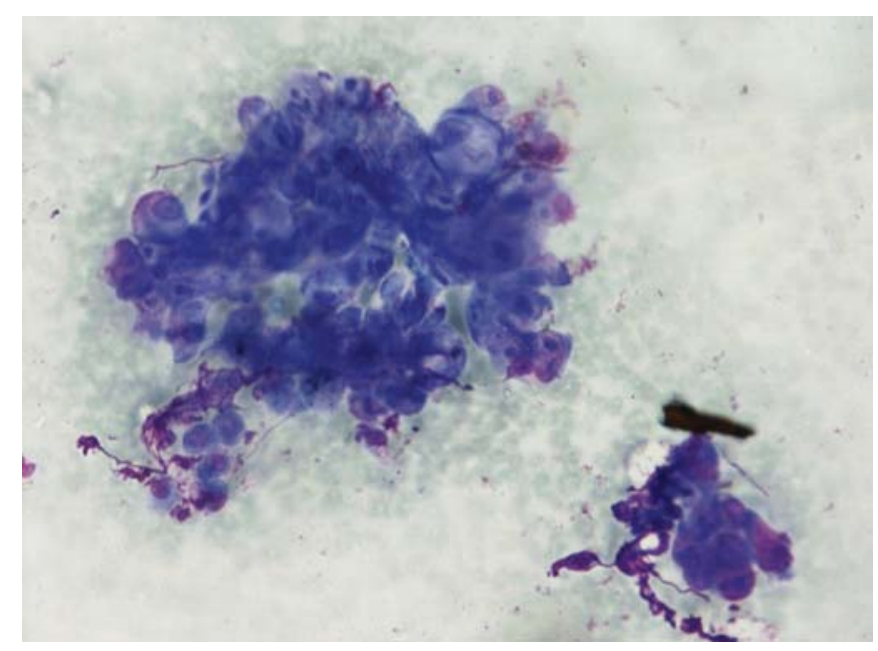

Fig. 3: A case of HCC showing malignant cells with macronucleoli at $400 x$

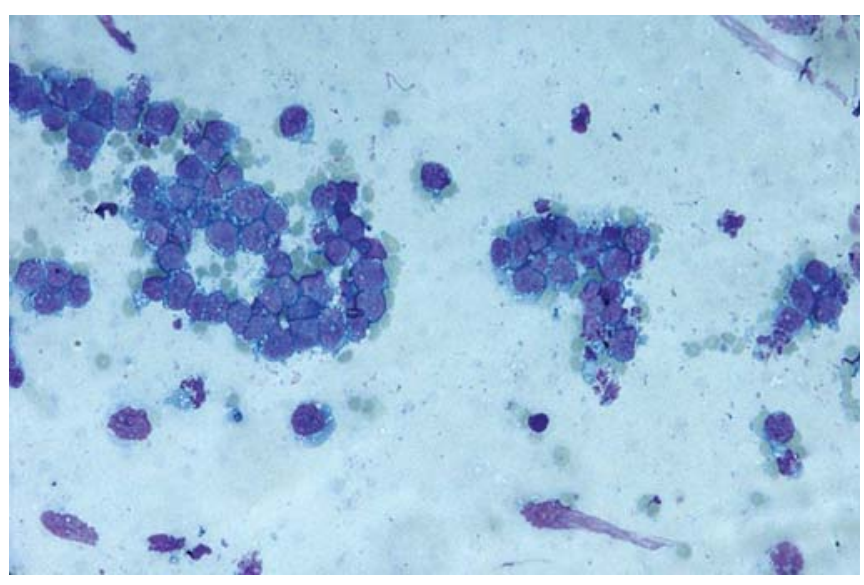

Fig. 4: A case of Burkitt's lymphoma showing cytoplasmic vacuolation of cells at $200 x$ 


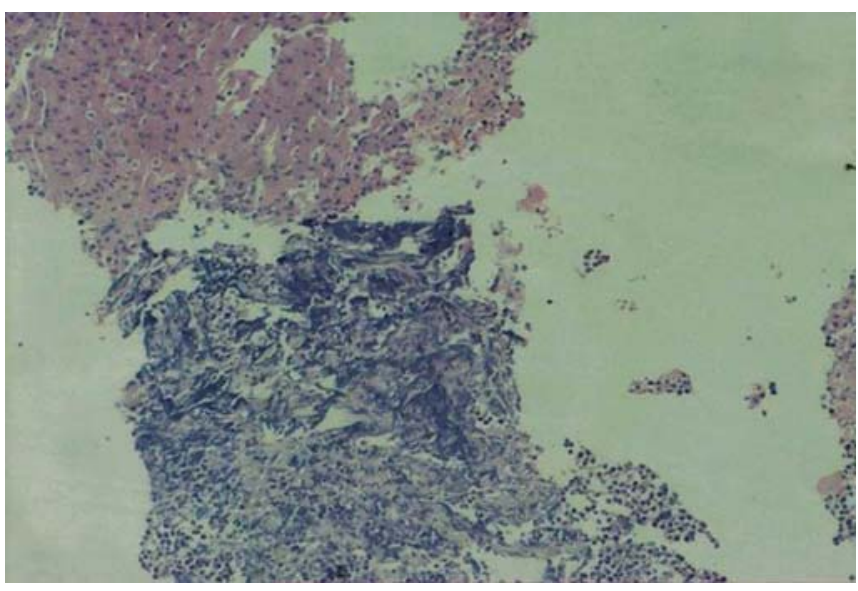

Fig. 5: Cell block preparation of Burkitt's lymphoma

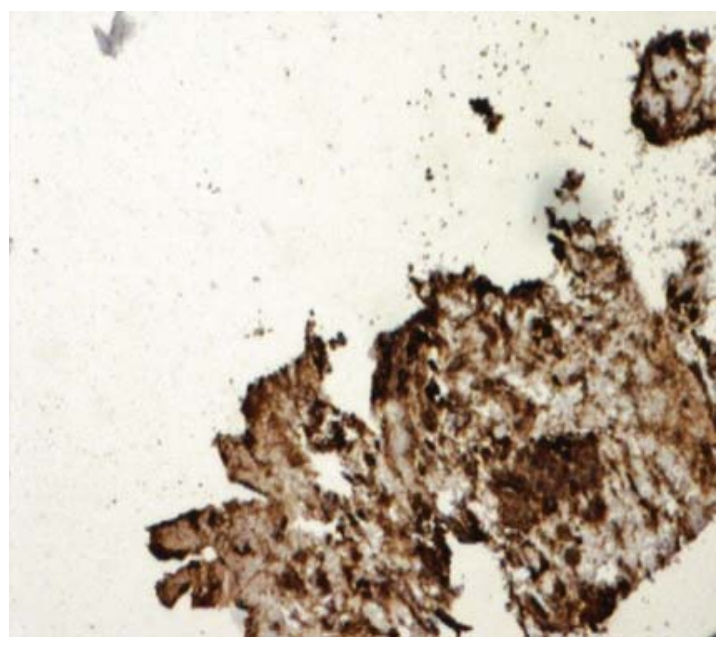

Fig. 6: HMB 45 staining of cell block preparation in malignant melanoma

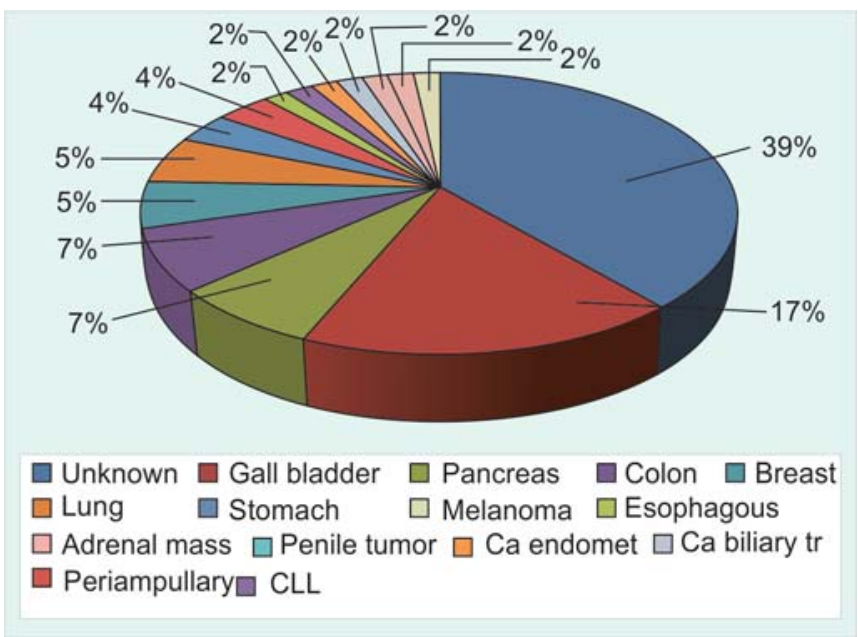

Fig. 7: Metastasis of various primaries to liver

features of liver abscesses, HCC and metastasis. Liver abscesses are impossible to differentiate from a neoplastic process radiologically. ${ }^{7}$ So, USG-guided FNA plays an important role which has been reported to be safe, useful and accurate technique for making cytological diagnosis of hepatic masses. ${ }^{8,9}$ It is used mainly for diagnosing hepatic malignancies primary or metastatic. ${ }^{10}$ However, without histological structures it is difficult on FNAC to determine the characteristics and classification of lesion. ${ }^{11}$ The use of cell blocks improved accuracy of detection of tumors as they have the benefit of providing multiple sections for immunocytochemistry. In addition IHC and special staining like PAS also helps in making diagnosis. ${ }^{12}$ FNAC has replaced conventional core needle biopsy to a large extent in diagnosis of focal lesions as multiple passes can be given to the patient in outdoor department. ${ }^{3}$ It can be used as early investigation in diagnosis of hepatic lesions as concluded by results of our study which are also supported by study done by Ding et al. ${ }^{13}$

FNAC was considered in various studies as less useful in diagnosing localized benign lesions as compared to malignant lesions. Swamy et al ${ }^{14}$ concluded that FNA C can accurately distinguish non-neoplastic from neoplastic lesions and categorize different non-neoplastic and different primary from metastatic tumors. In our study we found that if accurate diagnostic cellularity can be obtained then it can be used as accessory tool in identification of benign and inflammatory disease of liver. In our study out of diagnostic aspirates, three cases of inflammatory lesions were diagnosed which shows inflammatory cells, necrosis with debris. $\mathrm{H}$ epatocytes at periphery may show atypia. A bscess may simulate metastasis undergoing necrotizing degeneration.

A nother HB sA g-positive female was diagnosed for liver cell dysplasia. Cytological features show loosely arranged small fragments of hepatocytes which were enlarged and

Table 2: Categorization of malignant and benign lesions (67 cases)

\begin{tabular}{|c|c|c|c|}
\hline SI. no. & Types & No. of cases & Percentage \\
\hline \multirow[t]{2}{*}{1.} & $\begin{array}{l}\text { Non-neoplastic/ } \\
\text { Inflammatory lesions }\end{array}$ & & \\
\hline & Abscess & 03 & 04.5 \\
\hline \multirow[t]{2}{*}{2.} & Benign tumors & & \\
\hline & Liver cell dysplasia & 01 & 01.5 \\
\hline \multirow[t]{12}{*}{3.} & Malignant tumors & & \\
\hline & $\begin{array}{l}\text { a. Primary origin } \\
\mathrm{HCC}\end{array}$ & 04 & 06.0 \\
\hline & Burkitt's lymphoma & 01 & 01.5 \\
\hline & Cholangiocarcinoma & 01 & 01.5 \\
\hline & Total & 06 & 09.0 \\
\hline & b. Secondary origin & & \\
\hline & Adenocarcinoma & 22 & 32.8 \\
\hline & Poorly diff. carcinoma & 19 & 28.4 \\
\hline & Squamous cell carcinoma & 01 & 01.5 \\
\hline & Melanoma & 01 & 01.5 \\
\hline & Leiomyosarcoma & 01 & 01.5 \\
\hline & Total & 44 & 65.7 \\
\hline 4. & $\begin{array}{l}\text { Suspicious of secondary } \\
\text { malignancy }\end{array}$ & 13 & 19.4 \\
\hline
\end{tabular}


show marked variation in size and shape with prominent nucleoli, multi- and binucleated also. ${ }^{15,16}$

Das et al ${ }^{17}$ reported role of USG-guided FNAC in diagnosis and classification of liver malignancies and concluded that FNAC played important role in diagnosis and classification of malignancies in liver.

M ost common malignant lesion of primary origin was HCC in our study. Cytomorphologically it can be differentiated from other lesions of liver by the different features collectively like cellularity, acinar pattern, trabecular pattern, hyperchromasia, N/C ratio and cohesiveness of cells, nuclear shape and size, location, multinucleation, intranuclear inclusions, prominent nucleolus, amount of cytoplasm, vacuolation, bile production and hyaline bodies. The most important and helpful cytological features were the trabecular pattern, irregularly granular chromatin, multiple nucleoli and atypical naked nuclei as were described by Cohen et al. ${ }^{18,19}$

A primary case of Burkitt's lymphoma was also diagnosed in 28 years HIV -positive male. FNAC revealed cells having round nuclei, granular nuclear chromatin, multiple nucleoli and moderate amount of vacuolated dense blue cytoplasm. Diagnosis was later confirmed on histopathology. IHC show tumor cells positive for LCA, CD20, CD 10 and negative for B Cl2 and CD34. A case of cholangiocarcinoma was diagnosed and showed clusters of atypical cells resembling duct epithelium with desmoplastic stroma.

A mong the metastatic lesions adenocarcinoma were the most common diagnosed secondaries which showed glandular or acinar pattern, intra- and extracytoplasmic mucin. These tumors mainly came from the GIT, gall bladder, breast, lung and prostate. The special stain PAS and mucicarmine were done for glycogen and mucin as discussed in various studies. ${ }^{4,6,10}$

M etastasi from squamous cell carcinoma show ed large cell with multiple nucleoli inconspicuous with abundant basophilic cytoplasm with keratinization in a background of inflammation and necrosis.

M etastasis from malignant melanoma showed cellular smears comprising of loose cohesive clusters and singly scattered atypical cells. These cells were highly pleomorphic with variable cytoplasm showing brown black pigment as discussed in study conducted by $\mathrm{V}$ oit et al ${ }^{20}$ Diagnosis was confirmed after cell block preparation which on immunohistochemical staining for HM B 45 and S100 was positive.

Cellular smears comprising of oval- to spindle-shaped cells having pale ill-defined cytoplasm and pleomorphic nuclei arranged in loose cohesive clusters and scattered singly were found in case of metastasis from leiomyosarcoma. Primary was found later on in gut and diagnosis was confirmed on histopathology.

\section{CONCLUSION}

USG-guided FNA of liver is being increasingly accepted as valuable ancillary diagnostic tool that differs minimum risk and least discomfort to patient sitting at the outpatient department. Early definite pathological diagnosis of primary benign and malignant liver lesions and for tumors metastasis to liver can be made by assistance of cell block preparation and use of IHC. So that early management of hepatic lesions can be done. Thus, currently USG-guided FNAC is becoming primarily most important and can be used as first line of investigation for definite and early diagnosis of liver lesions.

\section{REFERENCES}

1. Rasania A, Pandey $C L$, J oshi N. Evaluation of FNAC in diagnosis of hepatitis lesion. J Cytol 2007;24:51-54.

2. Gatphoh ED, Gayatri S, Babina S, Singh AM. Fine needle aspiration cytology of liver: A study of 202 cases. Indian J M ed Sci 2003;57(1):22-25.

3. Asghar F, Riaz S. Diagnostic accuracy of percutaneous cytodiagnosis of hepatic masses by ultrasound guided fine needle aspiration cytology. A nnals 2010;16(3):184-88.

4. J ohansen $P$, Svendsen K N. Scan-guided fine needle aspiration biopsy in malignant hepatic disease. A cta Cytol 1978;22:292-96.

5. Kuo FY, Chen WJ, Lu SN, Wang JH, Eng HL. Fine needle aspiration cytodiagnosis of liver tumors. A cta Cytol 2004;48: 142-48.

6. A huja A, Gupta N, Srinivasan R, K al ra N, Chawla Y, R ajwanshi A. Differentiation of hepatocellular carcinoma from metastatic carcinoma of the liver-clinical and cytological features. J Cytol 2007;24(3):125-29.

7. Tchelepi H, Ralls PW, Radin R, Grant E. Sonography of diffuse liver disease. J Ultrasound M ed 2002;21(9):1023-32.

8. Shah A, J an GM. Fine needle aspiration cytology of liver. A study of 518 cases. J Cytol 2002;19:139-43.

9. Whitlach $S$, Nunez $C$, Pitlik D A. Fine needle aspiration of the liver. A study of 102 consecutive cases. Acta Cytol 1984;28: 719-25.

10. Y ousaf NW, J afri S, M asood G, M alik SA. The diagnostic role of fine needle aspiration cytology of liver in malignant focal mass lesions: A cytological correlation. JCPSP 2000;10:109-12.

11. Roy M, B hattacharya A, Gupta DS, Sanyal S. Fallacies of fine needle aspiration cytology of surgical lesions of liver. J Ind M ed A ssoc 1994;92:285-87.

12. Ceyhan K, K upana SA, B ektas M, Cobar S, T uzun A, Cinar K, et al. The diagnostic value of on-site cytopathological evaluation and cell block preparation in fine needle aspiration cytology of liver masses. Cytopathology 2006;17:267-74.

13. Ding W, HeXJ. Fine needle aspiration cytology in diagnosis of liver lesions. Hepatobilliary Pancreat D is Int 2004;3(1):90-91.

14. Swamy M, A rathi C, K odandaswamy C. Value of ultrasonography-guided fine needle aspiration cytology in the investigative sequence of hepatic lesions with an emphasis on hepatocellular carcinoma. J Cytol 20110 ct-Dec;28(4):178-84.

15. Anthony PP, Vogel LL, Barker LF. Liver cell dysplasia: A premalignant condition. J Clin Path 1973;26:217-23.

16. M akino Y, Shiraki K, Sugimoto K, I to T, Y amanaka T, Fujihawa $K$. Histological features of cirrhosis with hepatitis $C$ virus for prediction of Hepatocellular carcinoma development: $\mathrm{A}$ prospective study. A nti Cancer Res 2000;20(5C):3709-15. 
Profile of Liver Fine Needle Aspiration in Tertiary Care Hospital

17. Das DK, Tripathy RP, K umar N, et al. R ole of guided fine needle aspiration cytology in diagnosis and classification of liver malignancies. Trop Gatroenterol 1997;18:101-06.

18. Cohen M B, Haber M M , H olley EA, A hm DK, BottusK, Sitoloff AC. Cytologic criteria to distinguish hepatocellular carcinoma from non-neoplastic liver. A m J Clin Pathol 1991;95:125-30.

19. Noguchi $S, Y$ amamoto R, Tatsuta M . Cell features and patterns in fine needle aspirates of hepatocellular carcinoma. Cancer 1986;58:321-28.

20. V oit $C, M$ ayer $T$, Proebstle TM, W eber $L$, K eon $M, K$ rupienski $M$, et al. Ultrasound-guided fine needle aspiration in early detection of melanoma metastasis. Cancer 2000 J un 25;90(3): 186-93.

\section{ABOUT THE AUTHORS}

\section{Sunita Singh}

Department of Pathology and Radiology, Pt BD Sharma Postgraduate Institute of M edical Sciences (PGIM S), R ohtak, Haryana, India

\section{Rajeev Sen}

Department of Pathology and Radiology, Pt B D Sharma Postgraduate Institute of M edical Sciences (PGIM S), R ohtak, Haryana, India

\section{Sanjay Kumar}

Department of Pathology and R adiology, Pt BD Sharma Postgraduate Institute of M edical Sciences (PG IM S), Rohtak, Haryana, India

\section{Sumiti Gupta}

Department of Pathology and R adiology, Pt BD Sharma Postgraduate Institute of M edical Sciences (PGIM S), Rohtak, Haryana, India

\section{Sonia Chhabbra}

Department of Pathology and R adiology, Pt BD Sharma Postgraduate Institute of M edical Sciences (PGIM S), Rohtak, Haryana, India

\section{Monika Sangwan}

Department of Pathology and Radiology, Pt BD Sharma Postgraduate Institute of M edical Sciences (PG IM S), Rohtak, Haryana, India

CorrespondenceAddress H. N 0: 152, Jagat Colony, B hiwani-127021 Haryana, India, Phone: +919466336734, e-mail: dr.monika1311@yahoo.in

\section{Sunil Lamba}

Department of Pathology and R adiology, Pt BD Sharma Postgraduate Institute of M edical Sciences (PGIM S), Rohtak, Haryana, India 